\author{
Joanna Chojnicka \\ Adam Mickiewicz University in Poznań \\ j.a.chojnicka@gmail.com
}

\title{
Lower Sorbian (New) Speakers: Questions Worth Asking
}

\begin{abstract}
This article discusses the results of a sociolinguistic survey conducted among speakers of Lower Sorbian in autumn/winter 2020/2021. Lower Sorbian is an endangered Slavic language spoken in Lower Lusatia, a region located in the federal state of Brandenburg in eastern Germany. As is the case with many other minority languages, efforts are currently being undertaken to revitalize it and ensure its survival for future generations. Since home transmission of Lower Sorbian has practically ceased completely, the burden of revitalization is increasingly being carried by so-called new speakers, i.e. speakers who have acquired the language, usually via institutional education and often as adults.

The online survey, available both in Lower Sorbian and German, consisted of 30 questions divided into four sections: General information, Language use/linguistic practices, Lower Sorbian identity and community, and Opinions and attitudes. Its goal was to gather general information on the Lower Sorbian speaker community and on how it operates. Although the survey did not target new speakers specifically, it was expected to be completed mostly by this speaker group. It was designed to provide an overall picture of new speaker profiles, to be explored in depth later in the project during individual sociolinguistic interviews and focus group discussions. The questionnaire was distributed via familiar speaker networks and completed by 78 respondents (43 in German and 35 in Lower Sorbian).

As the number of Lower Sorbian speakers is not known, the results of the survey cannot be considered representative. They do, however, provide important and interesting information about a group of speakers who are mostly of working age, well-educated and living predominantly in Cottbus or the surrounding area. They make an effort to speak the endangered language in professional and social/cultural contexts, they are aware of its precarious situation and they care about its survival. Most of our respondents have learned the language - or are still learning it - via institutional education, which makes them new speakers. Through multiple diagrams that represent the survey results in an easy-to-follow way, complemented by examples of respondents' comments to the questionnaire, the article paints a general picture of these speakers, their motivations, language practices and future hopes and aspirations.
\end{abstract}

Keywords: Lower Sorbian; minority language; endangered language; revitalization; sociolinguistic survey

\section{The Sociolinguistic Situation of Lower Sorbian}

Lower Sorbian belongs to the Western branch of the Slavic subfamily of Indo-European languages, which also includes Upper Sorbian. Lower and Upper Sorbian are most closely related to Polish and Czech, respectively, and share some basic features with them, although the four languages are mutually intelligible only to a limited extent. The contemporary settlement area of Lower Sorbians, who migrated into the territory of present-day Germany in the sixth century, is located in the region of Lusatia (Lausitz)-Spreewald, in the three administrative districts of Dahme-Spreewald, 
Oberspreewald-Lausitz and Spree-Neisse, as well as the city of Cottbus/Chóśebuz (all in the federal state of Brandenburg).

Lower and Upper Sorbian (which is spoken in Saxony) have for a thousand years existed in a monolingual German political and cultural context. The state, the Protestant church and schools have always been German-speaking; Lower Sorbian could only ever exist as a language of family and community. Compulsory primary education and military service, as well as industrialization (especially the development of the coal industry), urbanization, and anti-Slavic prejudice have fostered the Germanization of the region (Marti, 1990, pp. 40-42).

In the Weimar Republic, conditions were favourable for the introduction of minority language protection, but Sorbian continued losing prestige and being associated with rural and folk culture while German represented modernity and progress. Under the Nazi regime, Sorbian organizations and publications were banned (Marti, 1990, p. 43) and children were punished for using the language at school (Glaser, 2007, p. 106).

After WWII, Lusatia became part of the GDR (communist East Germany); it was expected that it would become a bilingual socialist region within a couple of generations. Free Sorbian courses were offered in a variety of locations. However, in the context of advanced language shift facilitated by the creation of coal mines that destroyed around 100 Sorbian villages, an increase in mixed marriages, insufficient care paid to the language by churches and schools and an inefficient state bilingual policy (Lewaszkiewicz, 2014, pp. 47-48), Lower Sorbian neared extinction. Studies conducted in the 1990s estimated there to be 7,000 Lower Sorbian speakers, with approximately $60 \%$ of them over 60 years old (Lewaszkiewicz, 2014, p. 42). In 2000, the number of Lower Sorbian speakers was estimated at 5,000, and by 2010 the estimate was 2,000 (Dołowy-Rybińska, 2012, p. 47). The exact number of Lower Sorbian speakers today is not known; estimates range from 200 to 2000 active speakers. Lower Sorbian is classified as "definitely endangered" according to the UNESCO scale (Lower Sorbian in Germany, n.d.); there is a definite danger that it may cease to exist as a living language (Jodlbauer et al., 2001, p. 215).

It should be noted that Upper Sorbian has received more scholarly attention and is better documented than Lower Sorbian. Although also endangered, Upper Sorbian is in a better situation, since it still functions as the language of family and community in some villages (especially in Catholic areas). Sometimes, what is known about Upper Sorbian is understood to apply to Lower Sorbian as well, which results in an overly positive/optimistic view of the latter. This project is one of the few to focus solely on Lower Sorbian.

\section{Language Revitalization}

Lower Sorbian, like other endangered minority languages globally, is currently undergoing revitalization. The so-called Sorbian institutions - the Sorbian Institute, Maśica Serbska, and others - are working together to document, preserve and revitalize the language. The Witaj Language Centre is in charge of a Lower Sorbian immersion program in several kindergartens in Lower Lusatia, as well as teaching Sorbian in primary schools. It also trains teachers and develops teaching materials. Lower Sorbian exists in the media, especially in newspapers (the weekly Nowy Cas$n i k)$ and public radio (including the program produced by and for teenagers, Bubak). The role of Sorbian TV programs should not be over-estimated, as they are only broadcast for half an hour per month. Also, media consumption does not necessarily contribute to the development of active language skills, although the production of press articles and radio programs in Lower Sorbian often helps develop the creators' own language skills.

Lower Sorbian lacks a strong grassroots, bottom-up engagement. Many people of Sorbian heritage, due to a large extent to GDR state policy, assumed that it was the job of the state to take care of the language. GDR state policy is also often blamed for the failure of bilingual education. Another problem is the low prestige of the language and negative language attitudes represented by many people in Lusatia, including Lower Sorbian speakers (Jodlbauer et al., 2001, p. 215). 
Language revitalization is additionally impeded by the existence of two conflicting ideologies: the first believes that home language transmission is enough (which takes the pressure off schools) and the second believes that language classes in schools are enough (which justifies the lack of intergenerational home transmission). Some other conflicts discovered by Dołowy-Rybińska and Ratajczak (2019b) include the fact that native German speakers are often corrected on their Sorbian grammar, while at the same time being expected to avoid using German borrowings which Sorbian heritage speakers themselves use frequently. This can be very discouraging for native speakers of German who are trying to learn Lower Sorbian. Another conflict exists between the older generation's use of dialectal forms and the use of a literary standard at school. The literary standard is sometimes berated as "artificial", while local dialects can be seen as "uneducated" and "unsophisticated" (this will be examined more in the discussion of the survey results).

On a more positive note, recent years have seen some new, promising developments initiated mostly by young speakers of Lower Sorbian who have learned the language via the educational system and/or at the Institute for Sorbian Studies at the University of Leipzig - the only higher education program in Germany offering Sorbian languages. These initiatives include Serbske blido, a series of regular Sorbian-speaking meetings; the association of Sorbian-speaking families Gromaźe (there are currently about 10 families who transfer Lower Sorbian to their children at home); and, most recently, the Zorja project, a Lower Sorbian adult immersion program.

The present research project focuses on the motivations, practices and goals of "new speakers", people who adopt a language (often a minority one) that they have not learned from their parents or within their local community but at school, or even on their own as adults. New speakers often make a constant effort to speak the language regardless of their level of competence, identifying with the speech community while sometimes struggling to be accepted as legitimate members of it (Dołowy-Rybińska \& Ratajczak, 2019a, p. 3). New speakers are the welcome "product" of successful language revitalization, even if it must be kept in mind that the language they speak and transfer on will inevitably differ from the language of more traditional, "heritage" speakers (Jodlbauer et al., 2001, p. 215). The survey which is the focus of this article did not target new speakers of Lower Sorbian explicitly, as this would be difficult and limiting due to the fact that the term and the concept are not widely known outside academic circles. However, as there are very few heritage or traditional ("native") speakers left, one could expect new speakers - as well as learners and "supporters", since it was possible to complete the questionnaire without the knowledge of Lower Sorbian - to be captured and represented by it.

\section{The Survey}

The survey in question took the form of a questionnaire created using Google Forms software in two language versions (German and Lower Sorbian). It contained 30 questions divided into 4 sections. Additionally, each section contained space for comments. At the end of the questionnaire, respondents were asked if they would like to be contacted and offered the opportunity to participate in future focus groups and/or in-depth interviews. If the answer was "yes", the respondent was then asked to provide contact details.

The questionnaire included the following sections:

1. General information (11 questions),

2. Language use/linguistic practices (8 questions),

3. Lower Sorbian identity and community (7 questions),

4. Opinions and attitudes (4 questions).

The question formats ranged from multiple-choice questions with one or more possible answer(s), through open-ended questions with space for a short textual answer, to multiple-choice grids containing several statements that the respondents could agree or disagree with by choosing the most suitable option on a scale. In particular, the questions in section 4 contained between 6 
and 9 statements and an agreement scale of 5 options ("yes", "mostly yes", "undecided", "mostly no", and "no").

The questionnaire was preceded by a short introductory section containing information about the research project and the aims of the survey, as well as a data anonymization declaration. None of the questions were obligatory, but respondents were encouraged to answer as many of them as possible.

The questionnaire was distributed in autumn/winter 2020/2021 via the known network of contacts in Lower Lusatia, on several Facebook groups for Lower Sorbian speakers and on Twitter, as well as being advertised in several printed issues of Nowy Casnik and on its Facebook page. 78 people completed the questionnaire - 43 in German and 35 in Lower Sorbian.

\subsection{Section 1 - General Information}

The survey was completed by the same number of respondents identifying as female and identifying as male (38 each, with two respondents choosing not to say). The chart in Figure 1 illustrates their age distribution.

The survey reached no respondents aged under $15.9 \%$ of respondents were aged 24 or younger, and the same number of respondents were over 65 . The four "middle" age brackets, from 25-34 through 55-64, were all of a similar size, together amounting to $82 \%$ of the answers. This means that the majority of respondents were of working age.

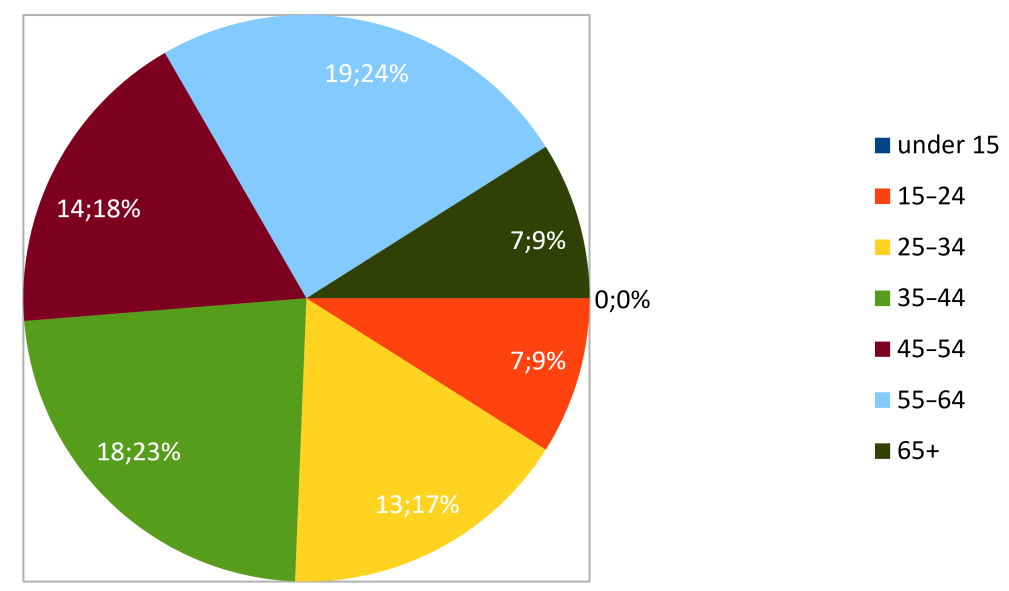

Figure 1. Age of survey respondents.

Section 1 next asked about the respondents' place of birth and current place of residence. Most respondents were born in Cottbus (23 or 29.49\%), Berlin and Forst (7 or $8.97 \%$ each). 6 respondents $(7.69 \%)$ were born outside Germany. In general, 49 respondents $(62.82 \%)$ were born within Lower Lusatia. One person did not answer this question.

At the time of answering the questionnaire, 25 respondents lived in Cottbus and 8 were resident in Berlin (32.05\% and 10.26\% respectively). Lower Lusatia was home to 54 respondents $(69.23 \%)$. It is striking how dispersed Lower Sorbian speakers appear to be: 77 people mentioned 31 different place names, and 25 of these places were mentioned only once or twice.

The question about profession was open-ended, returning many different options that we have tried to group into more general categories (in italics):

- manage/admin: managers, administration/office workers;

- researcher: historians, archaeologists (incl. Germ. Wissenschaftler/in); 
- culture: cultural/educators;

- linguist/translator: all professions related to language, also Germ. Lektor, Sorabist;

- pedagogue incl. social workers;

- religion: pastors, deacons (Germ. Pfarrer, Diakon);

- scientist: physicists, chemists, biologists.

In Figure 2, the results are represented separately - in orange for the German version and in yellow for the Lower Sorbian one, with the total for both versions in blue:

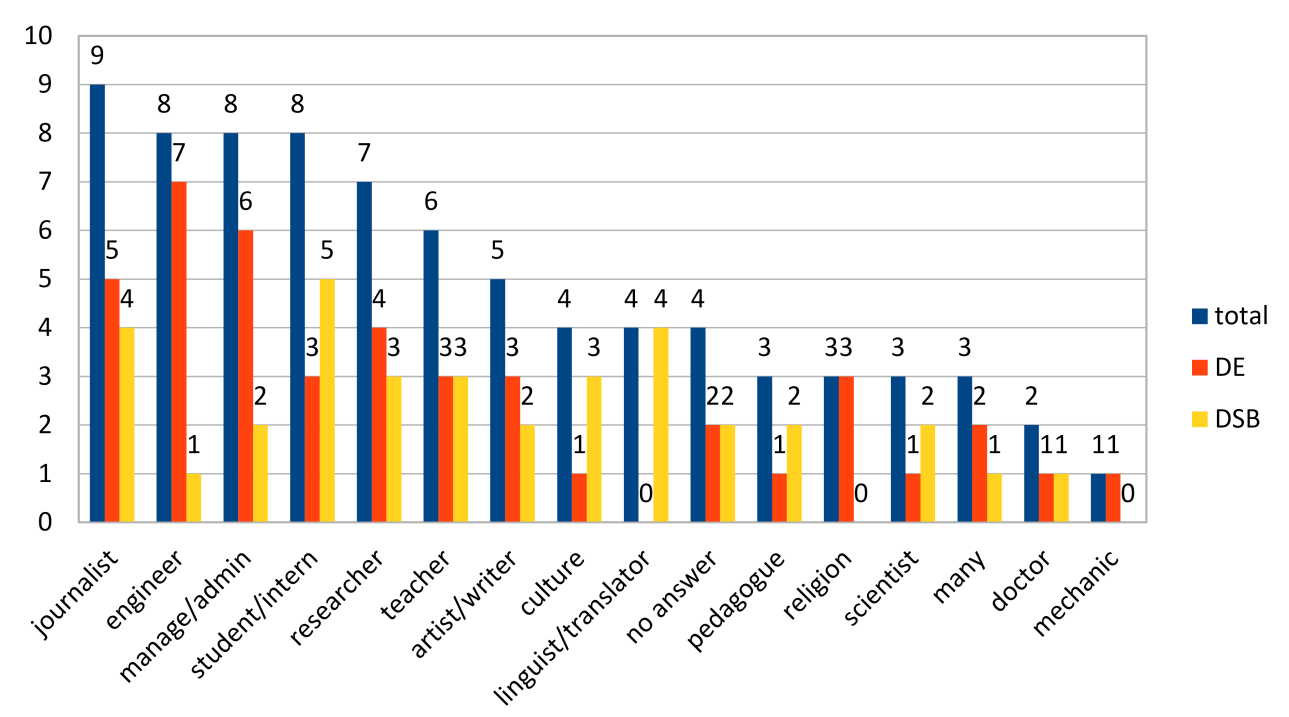

Figure 2. The respondents' professions.

Considering the two language versions separately can reveal some interesting patterns; e.g. almost all engineers chose the German version of the questionnaire, while all respondents claiming to work with language chose the Lower Sorbian version. Of course, one should not conclude too much from this: the mere choice of one language version over the other does not tell us anything about the given respondent's language skills or preferences.

The next question was concerned with language practices in the respondent's family of origin (Figure 3). Again, the results are represented separately for the German version (blue) and the Lower Sorbian version (orange). With the reservations expressed above in mind, it is fascinating that more people who chose the German version seem to have been spoken to in Lower Sorbian when they were children. This is especially visible when we consider the answers "mother", "father", "grandmother", "grandfather" and "no one".

A similar pattern emerges when we consider the next question - "Which languages were spoken to you as a child?". Twice as many respondents who chose the German language version, relative to those filling out the Sorbian one, were spoken to in Lower Sorbian as children (blue German, orange - Lower Sorbian version, Figure 4).

The next two questions in this section concerned language skills. The chart (Figure 5) illustrates our respondents' declared Lower Sorbian skills.

It is clearly visible that passive language skills (listening/reading) are assessed higher than active skills (speaking/writing). About $2 / 3$ respondents claimed to have very good or good passive skills $(64.10 \%$ for listening and $67.95 \%$ for reading) and well over half of them claimed to have very good or good active skills (55.13\% for speaking and $57.69 \%$ for writing).

There was also a related question about declared skills in several languages, including Lower Sorbian, Upper Sorbian and German. Here, $58.47 \%$ of the respondents declared native, very good 


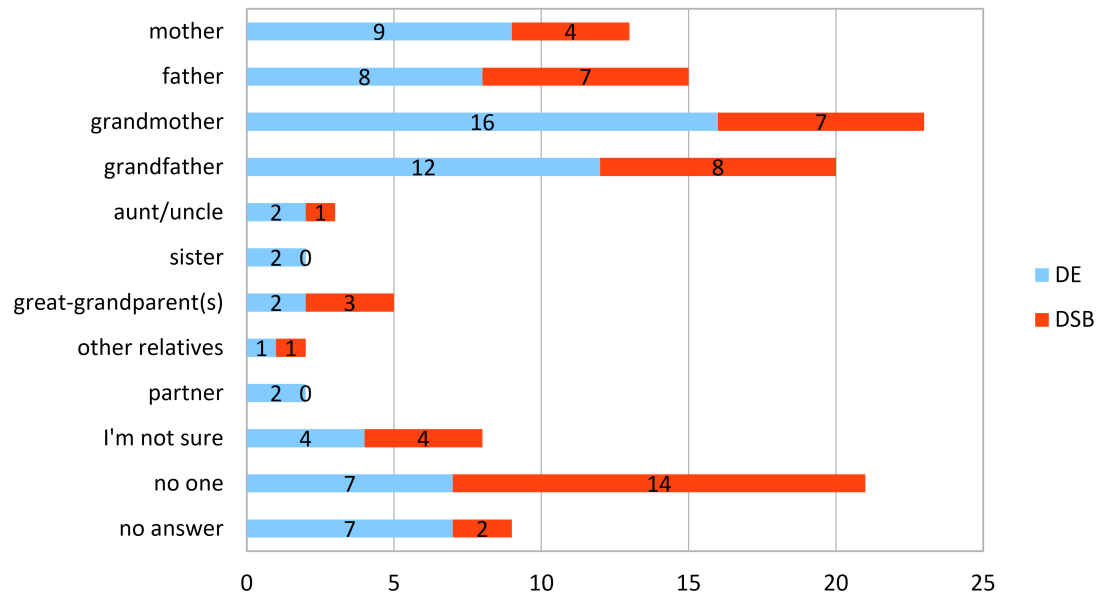

Figure 3. Lower Sorbian in the family of origin.

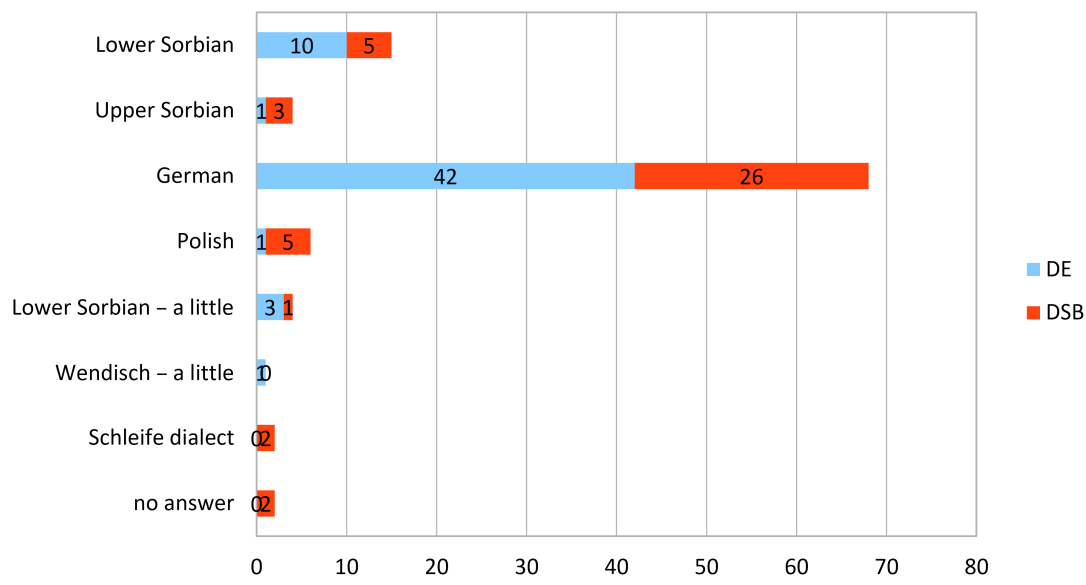

Figure 4. Languages spoken to respondents in childhood.

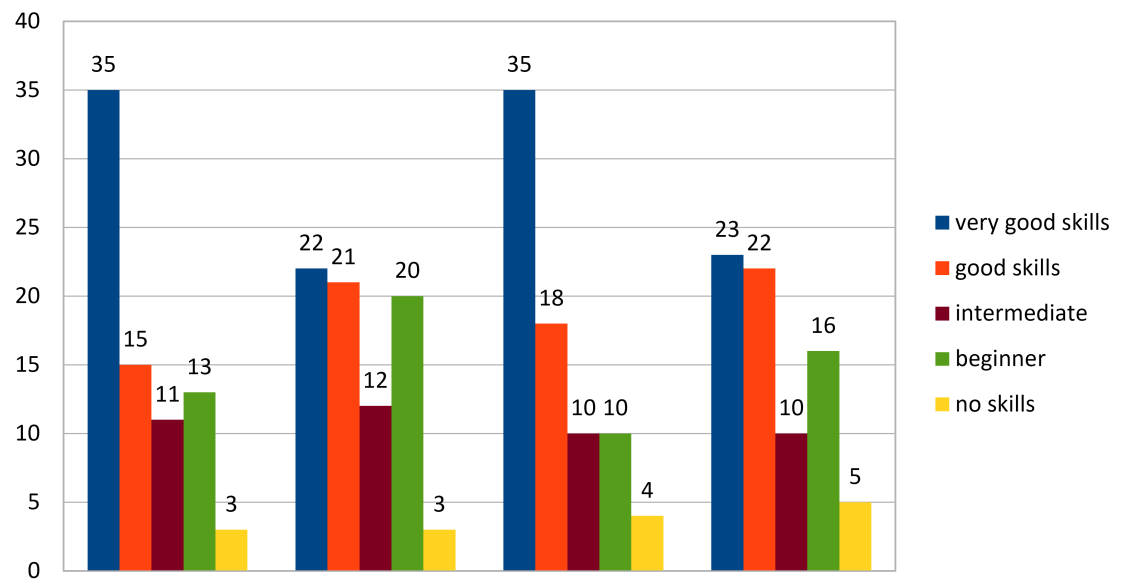

Figure 5. Survey respondents' declared Lower Sorbian skills. 
or good Lower Sorbian skills, which is consistent with the assessment of active Lower Sorbian language skills in the question above (Figure 6).

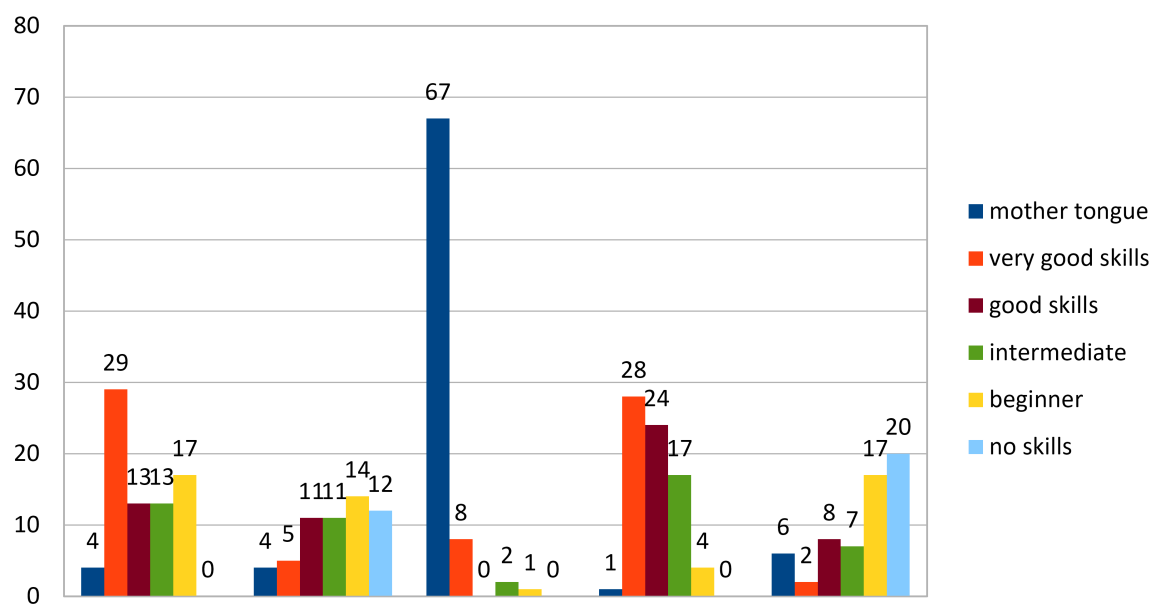

Figure 6. Survey respondents' declared skills in several languages.

That most respondents identified as German native speakers is unsurprising. What is interesting is that a very similar number of people declared good, intermediate and beginner skills in Lower and Upper Sorbian. It is safe to say that many of them are simultaneously learning both languages. The chart also shows that only 4 respondents $(5.19 \%)$ self-identify as native speakers of Lower Sorbian. Due to language shift there are very few people still able to claim native skills in Lower Sorbian, and most of them belong to an age group which is not represented in the survey (over 65).

In this section, we also asked about the respondents' experiences with formal Lower Sorbian education. We learned that:

- 5 respondents have attended a Witaj kindergarten (72 said they had not),

- 33 respondents have attended Lower Sorbian High School (44 said they had not),

- 53 respondents have participated in Lower Sorbian language courses (24 said they had not).

Since the Witaj project started in 1998, most of our respondents were too old to have experienced it. In order to do so, one would need to have been younger than 25 at the time of the survey, meaning that all 5 "Witaj children" were in the 15-24 age bracket.

In the comments to this section, many respondents elaborated on their answers, especially the ones concerned with languages spoken at home/in their childhood. The multiple-choice questions did not seem to do justice to the more complex language practices experienced by some respondents, e.g.:

(1) Depending on who was visiting us or whom we were visiting, I heard a whole lot of languages, among others Czech, Polish, Slovak, Russian, Ukrainian, English, Low German. For the most part the contact was sporadic. Many languages I also got to know through singing, I can still, for example, sing in Ukrainian and Belarusian.

In another comment, a respondent offers a succinct description of their learner's trajectory and current linguistic practices, which will be the subject of section 2 :

(2) My family was or still is against Lower Sorbian. They wanted or want to be German (...) I went to the Lower Sorbian High School but did not learn Lower Sorbian well there! I learned 
it on my own with the help of Sorbian courses, the paper and radio only later, about 5 years ago. The good Sorbian community helps a lot. We have good contact and meet at courses and events. (...) We also have an association for families. Also our children are involved. I try to speak Sorbian with them. (...) The School for Lower Sorbian Language and Culture helps a lot, we have the opportunity to meet. We also have a Lower Sorbian WhatsApp group.

The comment field was also used by some respondents to express their attitudes, which the questions in section 1 did not allow for:

(3) I only learned Lower Sorbian for 4 years in the Sorbian advanced high school in Cottbus. My German peers could learn German at school for 12 years. In the GDR this was called equality.

\subsection{Section 2 - Language Use/Linguistic Practices}

In this section, respondents were asked what activities they performed in Lower Sorbian, how often, with whom, what prevented them from using Lower Sorbian more often, whether they used it with their children and if so, why. As shown by Figure 7, a definite majority (73.08\%) of respondents use Lower Sorbian every day or a few times per week.

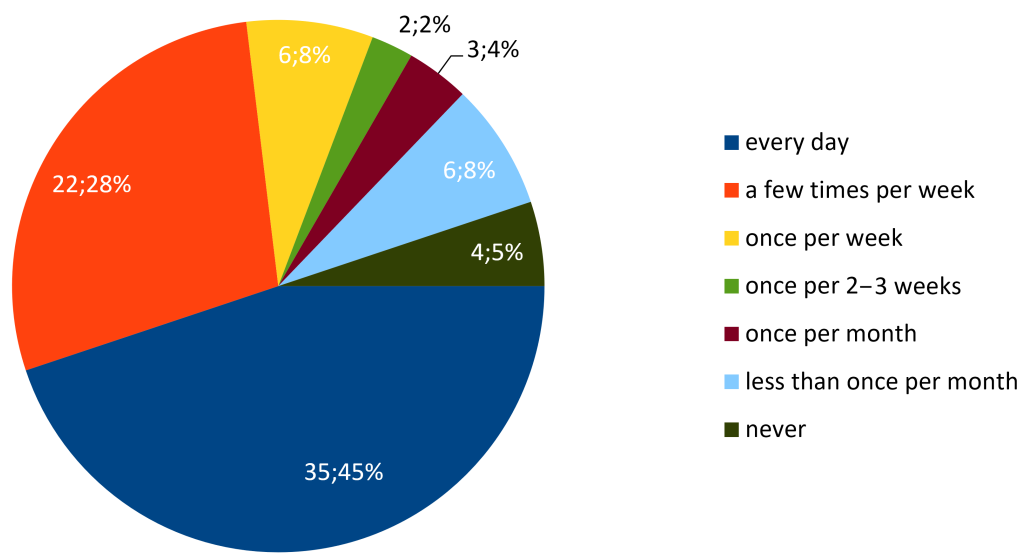

Figure 7. Frequency of use of Lower Sorbian.

Figure 8 shows different activities that the respondents perform in Lower Sorbian. It is interesting that reading and writing texts received the highest scores, suggesting that contact with the language is to a large extent textually mediated. While most respondents never prayed in Lower Sorbian, the number of people claiming that they never attended a Lower Sorbian mass was much lower. This could be explained with the fact that for many Lower Sorbian speakers, going to church is a social rather than a religious event, an opportunity to meet friends and have unmediated contact with Lower Sorbian. Praying could be assumed to be practiced by religious people only. Also, low scores for both "praying" and "swearing" could be explained by the fact that Lower Sorbian is the second language for most survey respondents and using an L2 in such emotional contexts is known to be difficult.

Figure 9 illustrates with whom our respondents speak in Lower Sorbian. It is striking that so few people declared that they used the language with their parents, partners and extended family. While the scores were slightly higher for friends, over $40 \%$ never or rarely used the language with them. A natural conclusion would be to assume that most respondents used Lower Sorbian with 


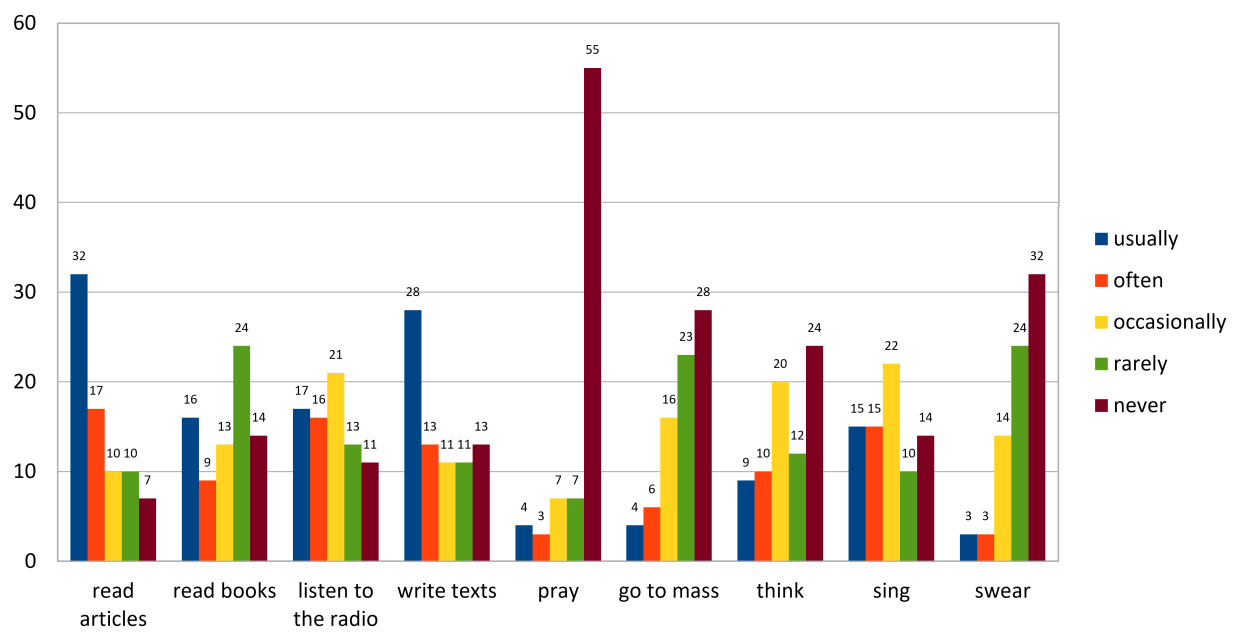

Figure 8. Activities in Lower Sorbian.

their colleagues at the so-called Sorbian institutions. Indeed, the next chart (Figure 10) shows that the work context received the highest score. Exactly $50 \%$ of respondents (39) spoke Lower Sorbian at work "usually" or "often". At the same time, however, only a slightly lower number (33, or $42.31 \%)$ of respondents "never" or "rarely" spoke the language at work. The question then arises: if not with family, friends or colleagues, with whom do the respondents speak Lower Sorbian?

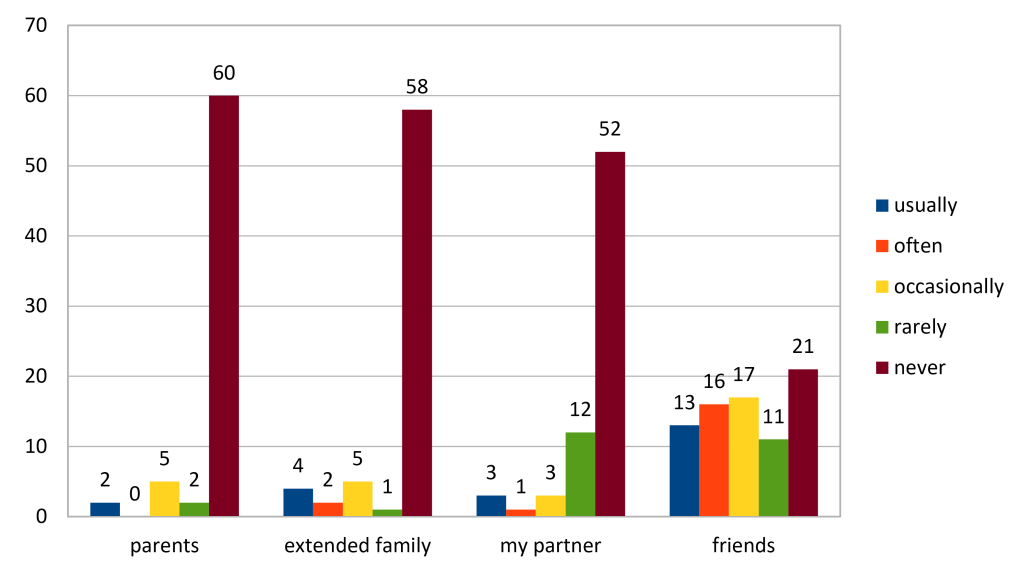

Figure 9. Lower Sorbian conversation partners.

The answer is given by Figure 10: community/cultural activities and Internet/social media contexts could provide Lower Sorbian conversation partners who were considered neither colleagues nor friends and thus were not accounted for in the other categories. These contexts probably also provide the rare Lower Sorbian language spaces, specifically created to speak or facilitate the use of the language (e.g. lectures, readings, Facebook or WhatsApp groups). Typical daily social contexts, such as meeting family, friends or talking to colleagues, constitute German-speaking spaces by default and are thus not conducive to using Lower Sorbian, with the exception of (some of) the Sorbian institutions. The Internet/social media contexts could also provide the text-based interaction with Lower Sorbian represented in Figure 8. 
If Lower Sorbian spaces are so difficult to come by, do speakers attempt to create them themselves, actively seeking opportunities to use the language? The answers to this question are represented in Figure 11, in yellow for the Lower Sorbian version, in orange for the German version, and in blue for the total.

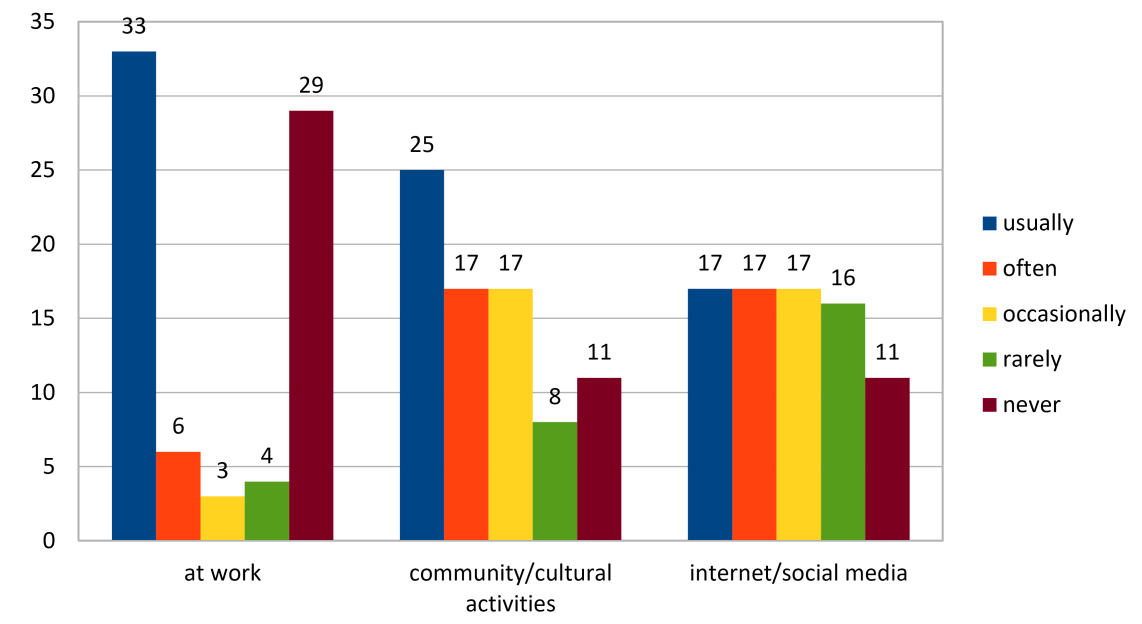

Figure 10. Situations in which Lower Sorbian is used.

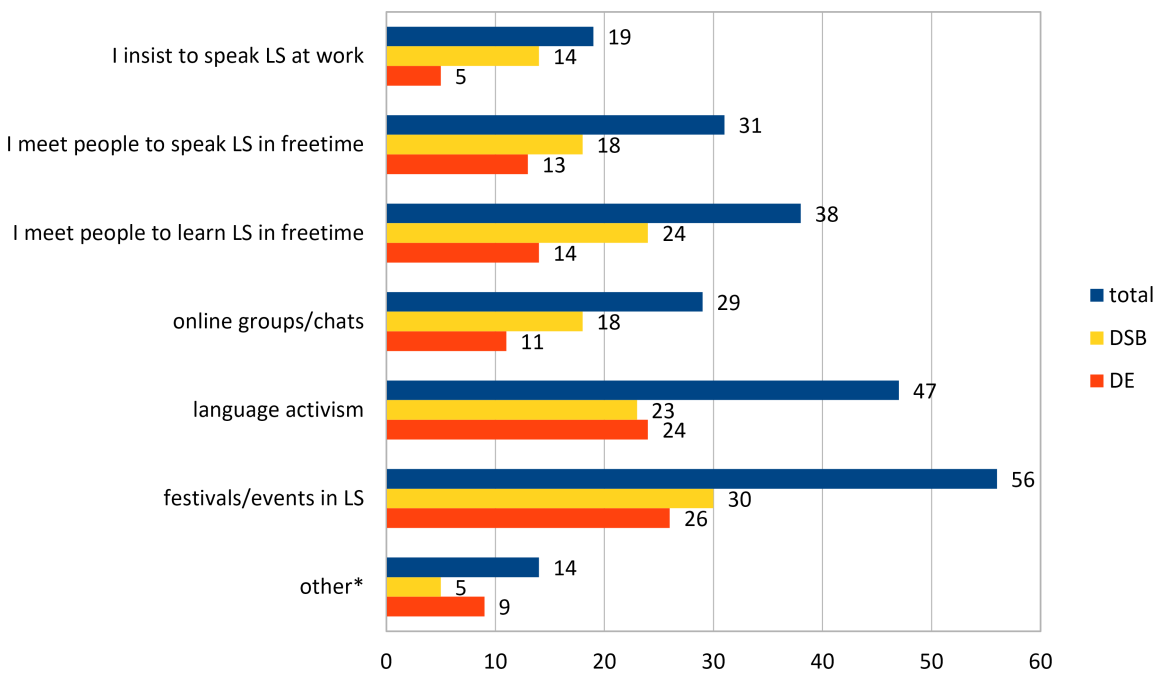

Figure 11. Ways to create opportunities to speak Lower Sorbian more frequently.

It is worth noting here that the scores in the Lower Sorbian version are higher than in the German one for almost all the available options (except "language activism" and "other"). Choosing the option "other" opened a field where respondents could type their own answers (14 in total), e.g.:

(4) I write for Lower Sorbian media.

(5) I write and publish Lower Sorbian literary texts. 


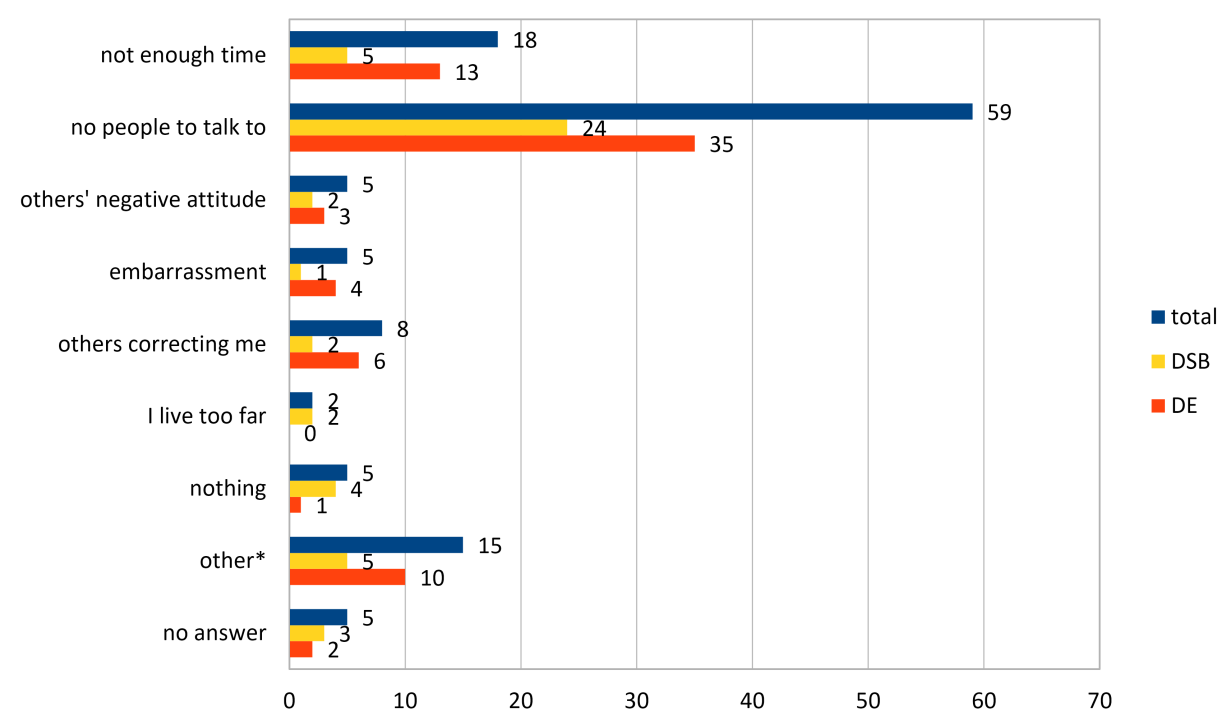

Figure 12. Factors preventing people from speaking Lower Sorbian.

(6) I'm active in associations and voluntary work.

(7) I organize Sorbian film evenings and work with Sorbian films.

(8) I sing Lower Sorbian songs with our group.

These answers illustrate yet again the importance of text-based interaction (writing for the media, writing literary texts) and community/cultural events (associations, voluntary work, Sorbian film evenings, songs) as contexts conducive to the use of Lower Sorbian.

Figure 12 represents the answers to the next question, "What prevents you from speaking Lower Sorbian more often?" Again, the answers are shown separately for Lower Sorbian and German versions (in yellow and orange, respectively) and in blue for the total. Here we see an opposite tendency to the one visible in Figure 11: the numbers in the German version are higher than in the Sorbian version for almost all the options. Again, choosing the option "other" made it possible to type one's own answer, 15 of which were received, e.g.:

(9) The constant German environment.

(10) There are not many opportunities outside work.

(11) There are not enough Sorbian-speaking spaces/opportunities to use the language.

(12) My colleagues, family, friends and acquaintances find it good that I cultivate the Sorbian language, but they do not speak it and have no motivation to learn it themselves.

Most additional answers boiled down to the same thing: there were not enough opportunities to speak Lower Sorbian, understood either as a lack of "spaces"/proper "environment" or as lack of conversation partners (incl. partners who speak the language well enough).

The next two questions concerned speaking Lower Sorbian with one's children. Almost half of the respondents (34 or 45.95\%) said they did not have any children. Only 3 people (4.05\%) spoke Lower Sorbian to their children "all the time" (the same number used it "half of the time"). One respondent (1.35\%) used the language "more than other languages" and $14(18.92 \%)$ used it "less than other languages". 19 people $(25.68 \%)$ did not use Lower Sorbian with their children at all.

The final question in this section, for respondents with children, concerned their reasons for speaking/teaching Lower Sorbian to them. Respondents could choose multiple options from the following list (Figure 13).

It is clear that Lower Sorbian culture was the most important reason. The least important was the possibility to communicate with relatives/neighbours in their mother tongue (possibly because 


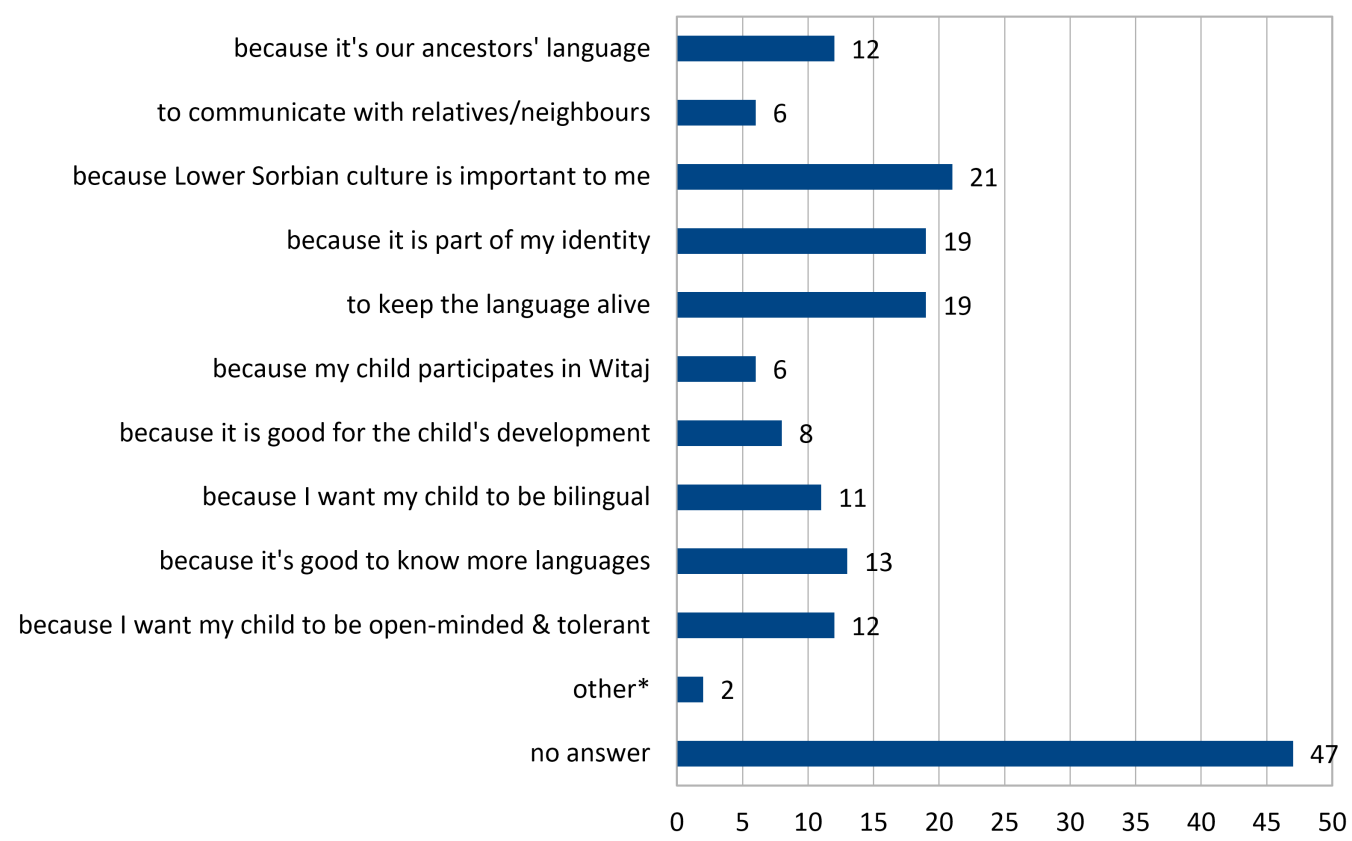

Figure 13. Respondents' reasons for speaking Lower Sorbian with their children.

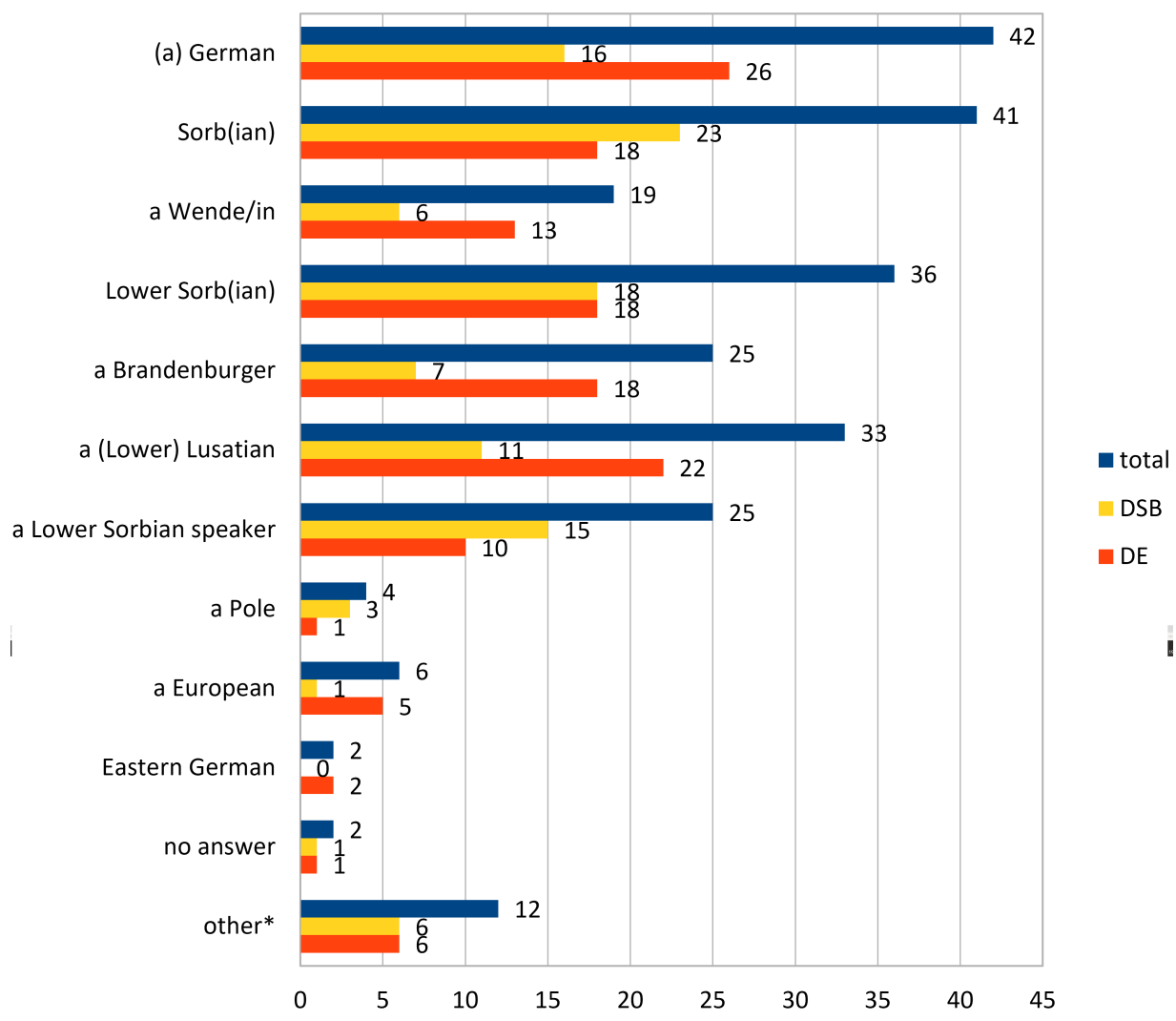

Figure 14. Answers to the question "you identify as...". 
there are very few such speakers left) and the fact that the child goes to a Witaj kindergarten/class (possibly because Witaj is generally not considered conducive to the children's acquisition of active Lower Sorbian skills, cf. Hornsby et al., in press).

In the comments to this section, many childless respondents emphasized that they would like to speak Lower Sorbian to their children once they became parents. As there are currently only several families raising children in Lower Sorbian, every new parent using the language at home would be a gain for Lower Sorbian revitalization. However, it must be kept in mind that home transmission in isolated families is very difficult and has little chance of succeeding, which respondents are aware of:

(13) For an active use of language with children other people are necessary. It is a pity when they are isolated, without contact to Sorbian speakers at the time when they are young, and it's only possible if both father and mother speak at the native-speaker level.

(14) My child wants me to speak Sorbian only when other Sorbian speakers are present. That's why for us the meetings with other Sorbian-speaking people are very important.

Other comments seem to express regret and provide justifications (or excuses?) for what is perceived as "not doing enough" for the language:

(15) I didn't manage to start speaking Sorbian with my children, I activated the Sorbian language for myself as an adult - but my children did not benefit from that, which I regret a lot.

(16) When I come back from work, where we speak Wendish all day, then I actually gladly speak German again. Besides I can express myself in German better/more elaborately in spite of all my Wendish language skills.

It is possible that some of our respondents interpreted certain questions as evoking particular norms or expectations pertaining to "proper" Lower Sorbian speakers ("they should actively seek opportunities", "they should speak the language (more) often"), which is why they felt compelled to justify their failure to fully comply with these norms and expectations in the comments field.

\subsection{Section 3 - Lower Sorbian Identity and Community}

In this section, the respondents were first asked how they identified themselves. They could choose more than one option in the multiple-choice list and add their own answers. The choices checked in the questionnaire are represented in Figure 14, with answers in the German version in orange, Lower Sorbian in yellow, and the total in blue.

Most respondents identify as German (42 or $53.85 \%$ ), but only one person less identifies as Lower Sorbian (41, or $52.56 \%$ ). The alternative label for Lower Sorbs which exists only in German - sg. Wende/Wendin and pl. Wenden - was less popular, especially in the Lower Sorbian version (in spite of "experiencing a strong renaissance" in the 1990s, cf. Norberg, 1996, pp. 28-29). It is interesting that 25 respondents $(32.05 \%)$ identify with the Brandenburg Land and $33(42.31 \%)$ with the region of Lower Lusatia, despite the fact that these local/regional identities were generally rejected in conversations we conducted with Lower Sorbian speakers.

The next question asked what was necessary in order to be able to identify as (a) Lower Sorbian (or Wende/Wendin). Here, six statements were provided, and respondents could choose between three reactions: "yes", "no" and "not sure" (Figure 15). For almost every statement, there were more negative reactions than positive ones, suggesting that identifying with "Sorbianness" depends largely on other criteria, not captured in the survey. Furthermore, criteria associated with linguistic and cultural practices, such as speaking and especially understanding the language, as well as observing traditions and customs, received the most positive reactions, which could suggest that one's actions and practices are more important in this regard than more objective factors, e.g. being born in a particular place. 


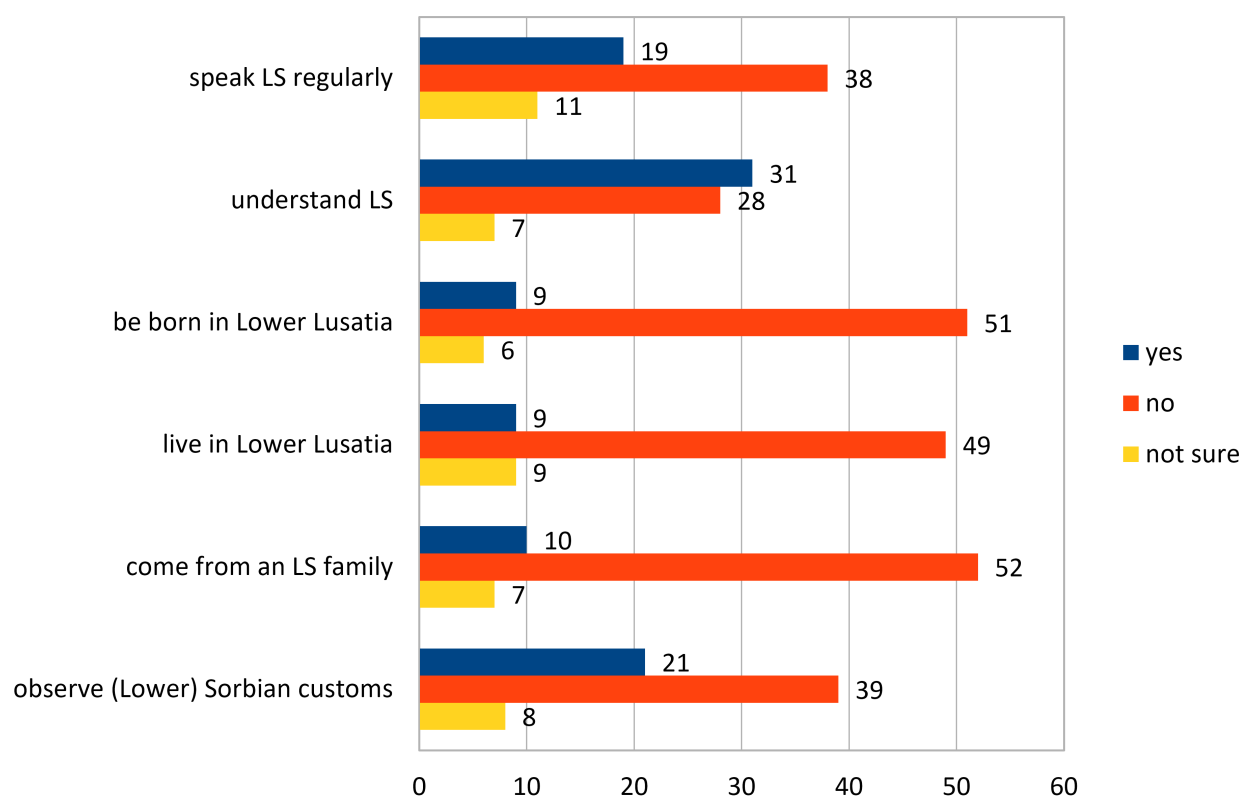

Figure 15. In order to be able to identify as (a) Lower Sorbian, it is necessary to...

The next two questions attempted to capture a division or even a conflict existing in many minority language contexts between the so-called traditional (dialectal) and modern (standard) language varieties. A phenomenon reported for many languages undergoing revitalization is the inability of traditional/heritage speakers and speakers who have learned the language through the educational system to understand each other (e.g., Hornsby, 2015). In the Lower Sorbian community, there is an awareness that "native speakers" are a group of just a few older, isolated village dwellers. "Native speakers" represent an ideal rather than a reality, although their way of speaking Lower Sorbian is still considered by many to be the model of "proper" Sorbian. Traces of this way of thinking can be found in the comments for this section, e.g.:

(17) The Lower Sorbian of native speakers sounds wonderful.

(18) With native speakers I can hear authentic phonetics.

On the other hand, there was an equal number of comments to the effect that all Lower Sorbian speakers are valuable and even that reproducing the stereotypical division is harmful:

(19) I speak gladly with everyone. What's such a ranking for?

(20) In general I gladly speak with everyone who speaks Lower Sorbian or takes the effort [to learn it].

(21) Every linguistic contact contributes to the maintenance of one's language.

Figure 16 shows that when asked about the frequency of speaking with different categories of speakers, our respondents favoured the option "occasionally" for almost all of them — natives, learners and beginners. At the same time, respondents seem to speak most frequently with fluent speakers and least frequently with native speakers.

Figure 17 shows how gladly respondents speak with the same categories of speakers. While native speakers received by far the highest scores, the results become very similar when we consider the options "most gladly" and "very gladly" together (50 or $64.10 \%$ for native speakers and 49 or $62.82 \%$ for fluent speakers). This reflects the ambivalence with regard to the native speaker ideal expressed in the comments and discussed above. 


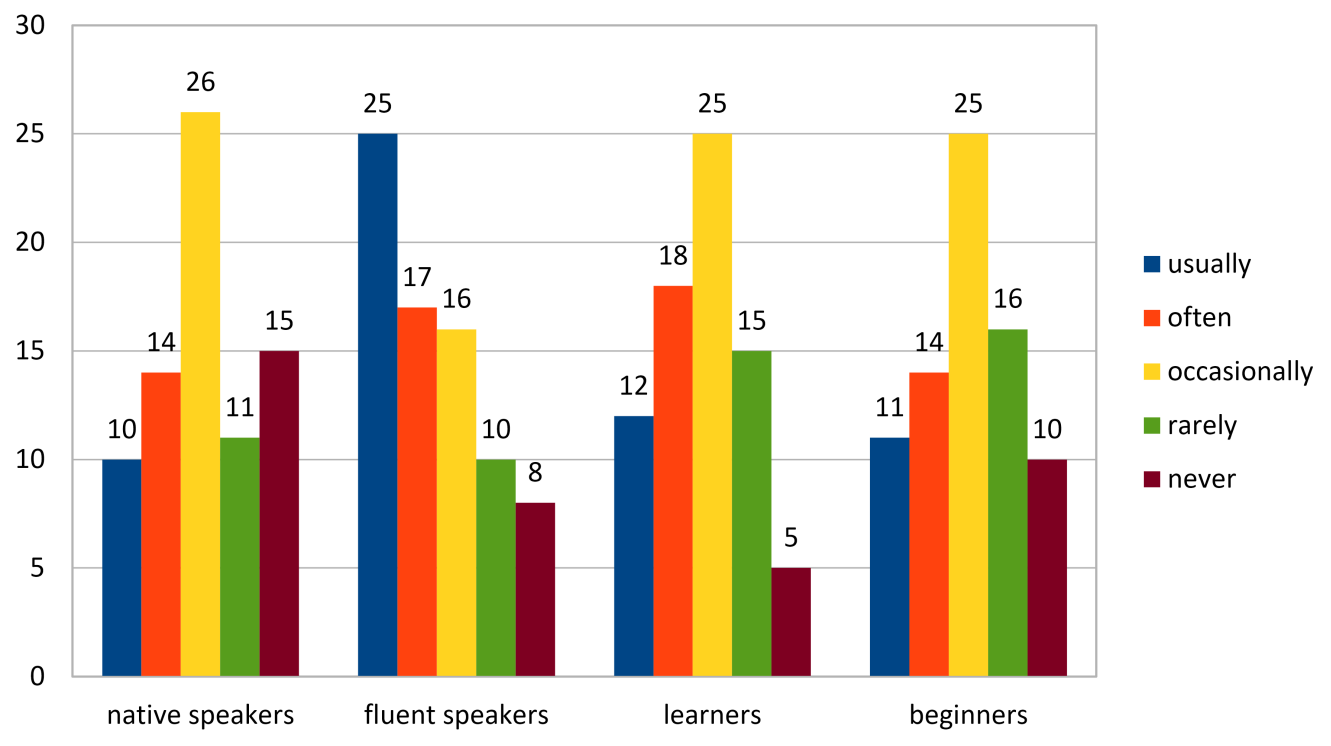

Figure 16. How often do you speak Lower Sorbian with...

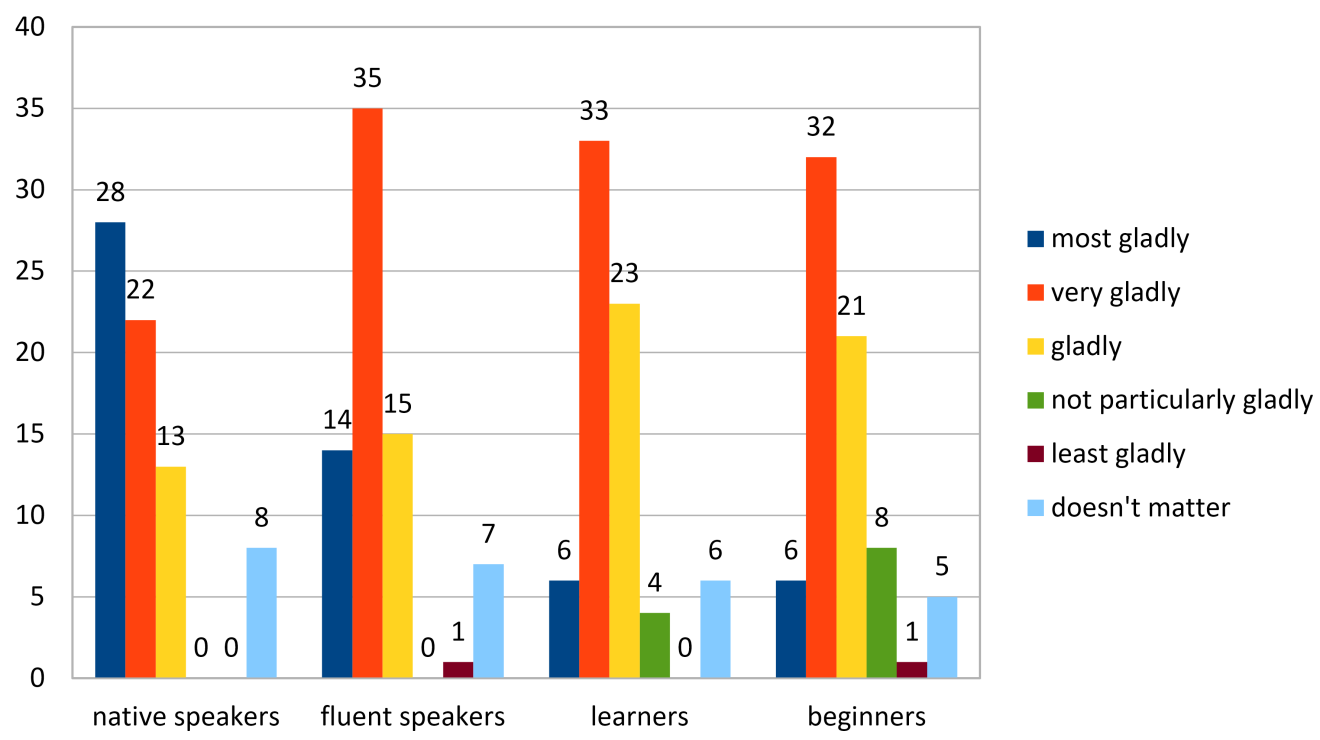

Figure 17. How gladly do you speak Lower Sorbian with... 
The next two questions concerned the community of Lower Sorbian speakers. Firstly, 68 respondents (86.08\% "yes" answers) agreed that such a community existed, 1 (1.27\% "no" answers) said that it did not and $10(12.66 \%)$ were not sure.

The respondents who answered "yes" were then asked to agree or disagree with a set of statements concerning this community, the results of which are shown in Figure 18 below.

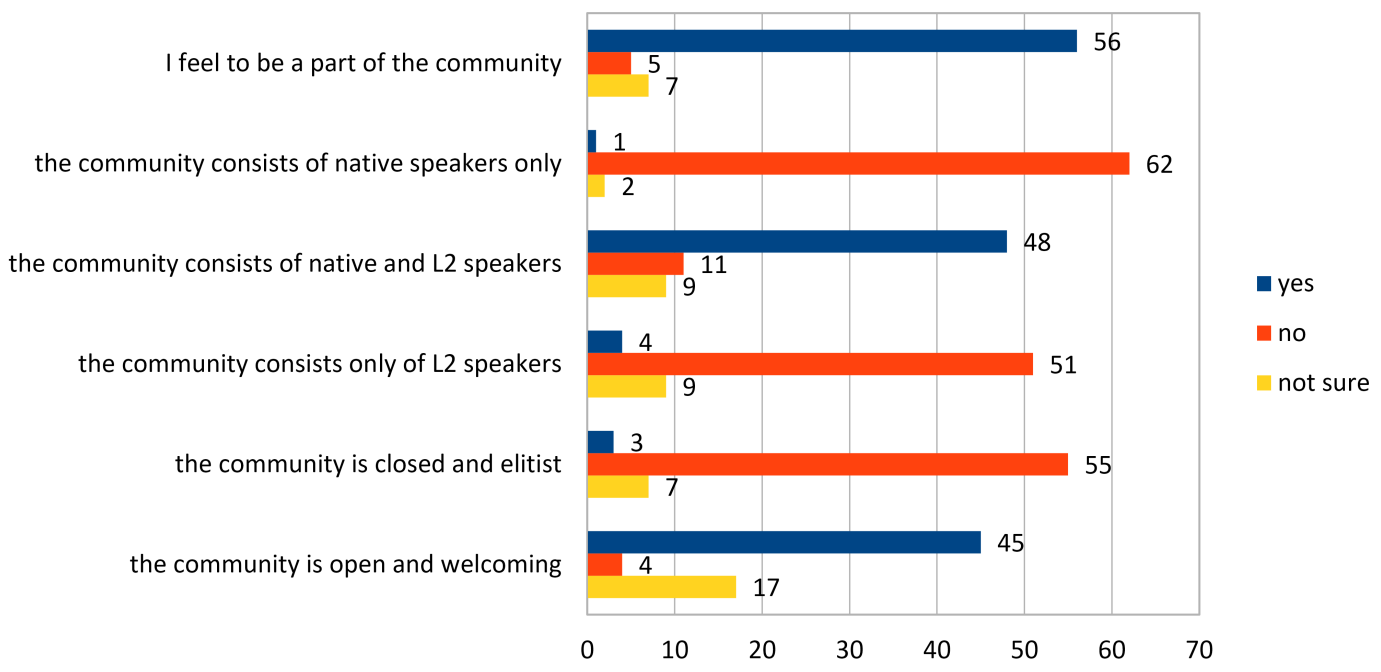

Figure 18. Statements concerning the community of Lower Sorbian speakers.

The chart shows that the respondents were quite uniform in their reactions to these statements, declaring their perceived belonging to the community, which consists of both native and L2 speakers (new speakers, learners) and is open and welcoming rather than closed and elitist.

In the comments to this section, our respondents again took the opportunity to elaborate on their answers and choices, e.g.:

(22) None of the mentioned criteria ON ITS OWN is necessary for someone to feel Sorbian, but the more criteria are fulfilled, the stronger the identity is.

The comments focused mostly on two issues in the third section - the "criteria" of identity (example (23)) and the nature of the community of Lower Sorbian speakers (example (24)):

(23) In order to identify as a Sorb it is necessary for people to occupy themselves with the Sorbian language and try to learn it. It is normal that not everyone can speak the Sorbian language at a high level of proficiency.

(24) When it comes to the old native speakers, I do not always know if they consider themselves part of the Sorbian/Wendish language community.

The following two comments seem to express contradictory views concerning the "openness" or "closedness" of the community: example (25) suggests that certain parts of it do not welcome new speakers, while example (26) suggests that the community is too welcoming, which makes it impossible to actually practice Lower Sorbian:

(25) There are still individuals in the Lower Sorbian language community (as in every other language community too) who are not particularly open towards people who do not come from Lower Lusatia. 
(26) These days it seems to me that everyone who occupies themselves with the Sorbian language is welcome, never mind how little they know. But when you try to create linguistic spaces where Sorbian should have priority, this leads to heavy conflicts with people who feel excluded because they do not speak Sorbian well enough.

\subsection{Section 4 - Opinions and Attitudes}

This section consisted of four sets of statements that could be responded to using one of five available options: "yes", "mostly yes", "undecided", "mostly no", and "no".

The first set was concerned with Lower Sorbian in Lower Lusatia and contained the following statements (Figure 19):

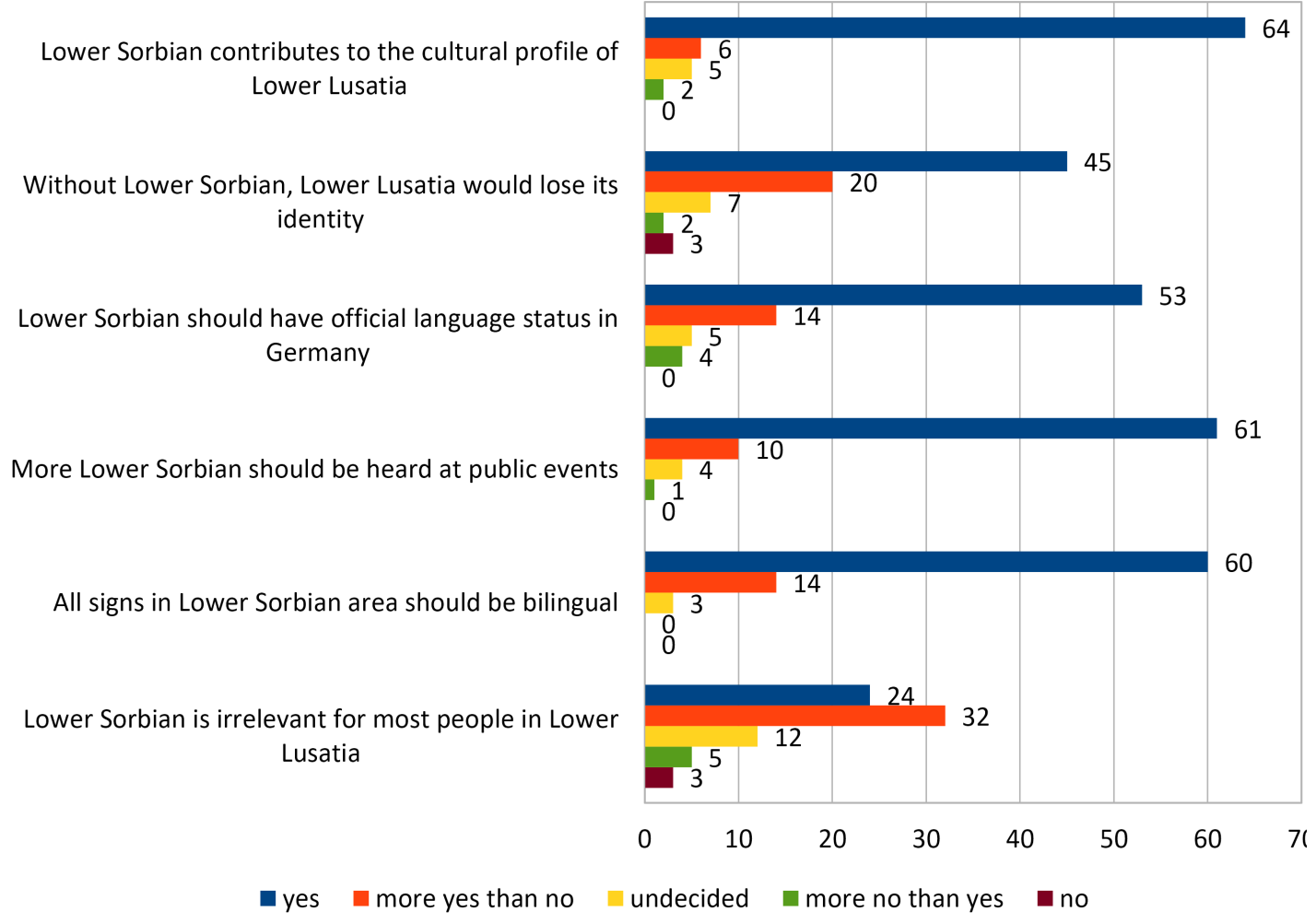

Figure 19. Lower Sorbian in Lower Lusatia.

Most respondents agreed with all the statements, including — somewhat surprisingly - the last assessment (which stood out as being rather negative), although here the number of "yes" answers was definitely much lower than for the other statements.

The second set of statements referred to the perception of and attitudes towards Lower Sorbian and consisted of the statements listed in Figure 20.

Only the first statement met with decisive agreement from the majority of respondents; for the other statements, the results were more varied across the whole scale of options.

The third set of statements pertained to Lower Sorbian language acquisition (Figure 21).

It is clear that statement E) received the most enthusiastic reaction with 65 "yes" answers, followed by statements B) and F), which scored 37 and 36 "yes" answers, respectively. The other statements received more varied results. 


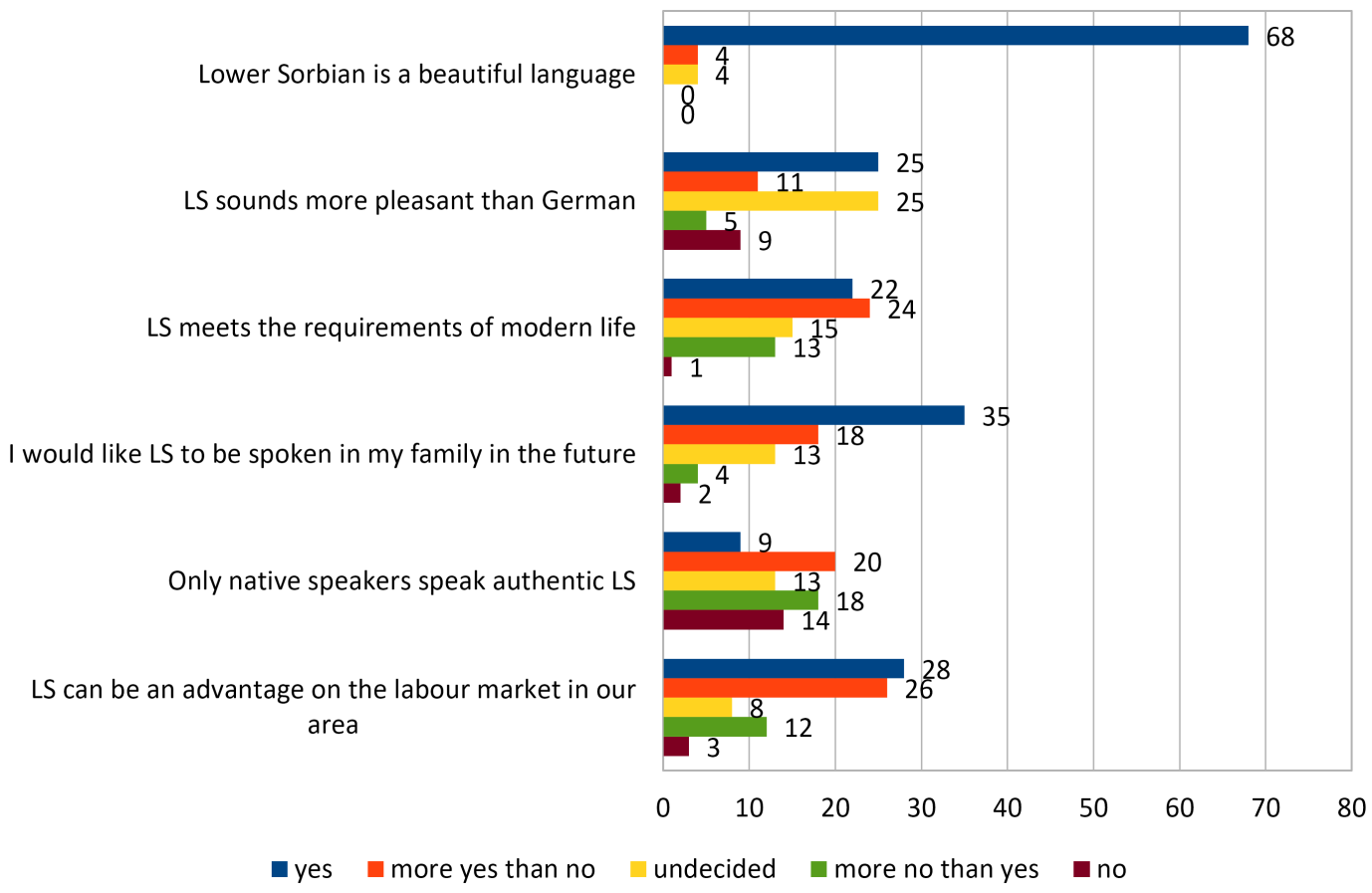

Figure 20. Perception of and attitudes towards Lower Sorbian.

A)

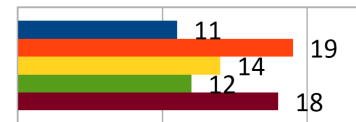

B)

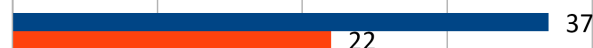

C)

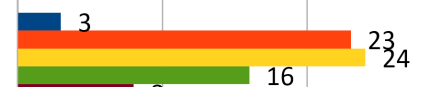

D)

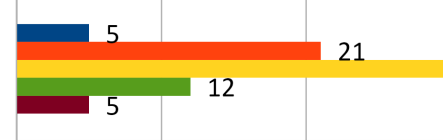

30

E)

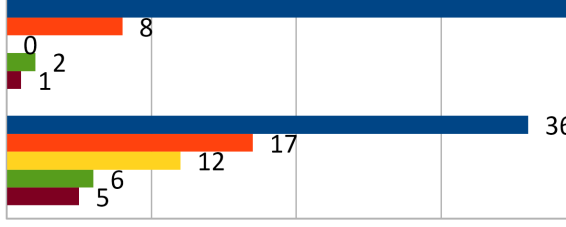

$0 \quad 10$

20

30

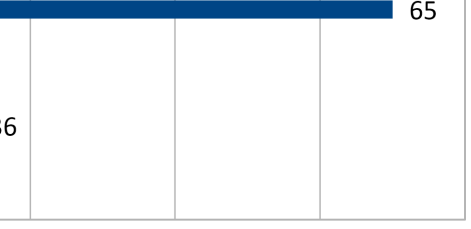

-yes

more yes than no

undecided

more no than yes

no

A) Lower Sorbian is harder to learn than English or French.

B) The fact that Lower Sorbian is hardly ever acquired in the family today has a negative effect on the quality of the language.

C) School-based Lower Sorbian is artificial.

D) Correct and proper Lower Sorbian is taught at school.

E) All children in the Lower Sorbian settlement area should have the opportunity to learn Lower Sorbian in school.

F) Participation in Lower Sorbian lessons should be compulsory in our region up to a certain age.

Figure 21. Lower Sorbian language acquisition. 
The final set of statements was concerned with Lower Sorbian language maintenance and revitalization (Figure 22).

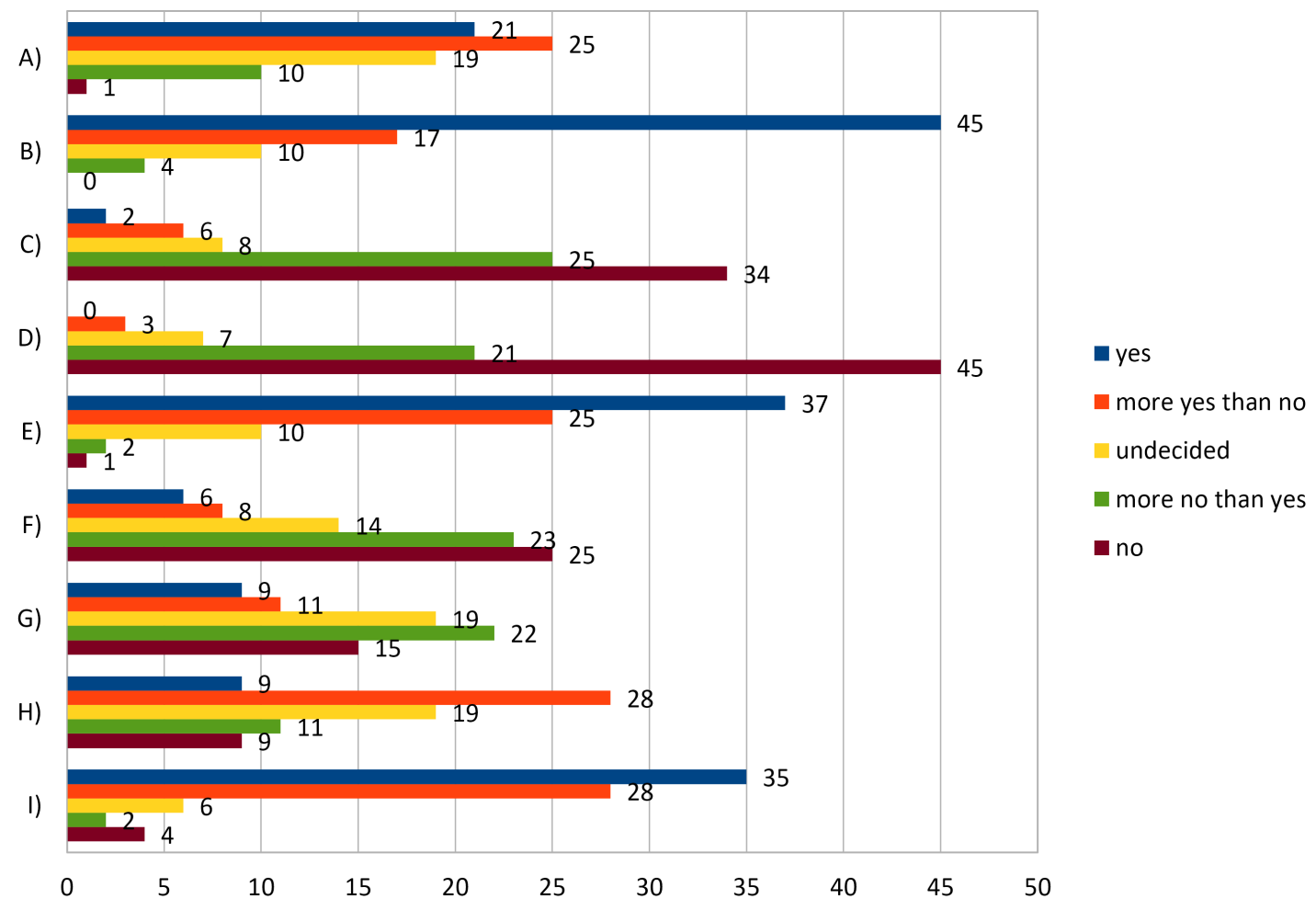

A) The current level of official support for Lower Sorbian may delay its complete decline, but ultimately cannot prevent it.

B) Every Sorb (Wende/Wendin) should get involved in the promotion of Lower Sorbian.

C) Speaking Lower Sorbian at home is enough to maintain it.

D) It is enough to learn Lower Sorbian at school to maintain it.

E) Lower Sorbian would have a better chance of survival if non-speakers had a more positive attitude towards it.

F) The (Lower) Sorbian culture can exist without the Lower Sorbian language.

G) The main responsibility for maintaining Lower Sorbian rests with the political decision-makers.

H) The main responsibility for maintaining Lower Sorbian rests with parents.

I) The main responsibility for maintaining Lower Sorbian rests with everyone who can (still) speak Lower Sorbian.

Figure 22. Lower Sorbian language maintenance and revitalization.

It should be noted that surveys and other quantitative methods are imperfect tools for measuring attitudes: they may ask for opinions on issues that respondents have never thought about, "conjuring" these opinions into existence rather than merely documenting existing attitudes; questionnaires often force respondents to adjust their opinions to a fixed matrix, which is not how they normally imagine them (e.g. Coleman \& Ross, 2010). Qualitative approaches, such as focus groups and in-depth interviews, can tell us more about attitudes and opinions held by individuals, allowing them to describe their perspectives on their own terms. A survey, however, can provide useful background information and help anchor a more in-depth conversation.

Some respondents drew attention to the weaknesses of the survey format in the comments. For instance, they emphasized that some questions were unclear or imprecise (example (27)), or could not do justice to the full complexity of a given situation (example (28)). It may be said, however, that by providing the opportunity to elaborate, the comment fields alleviated these weaknesses to a certain extent. 
(27) For example, 4.2.5 - what is "authentic language"? Or 4.3.1: is Sorbian difficult because of the language itself (Slavic language as a difficult language) or because of the circumstances (e.g. it is easier to be exposed to English music or movies because they are there).

(28) How the language sounds: I wouldn't say that one can generalize that. To me personally, the native speakers' Sorbian in Drachhausen or Drehnow sounds better than the German of a German native speaker from Cottbus. BUT: A nicely spoken Bavarian dialect also sounds better to me than a coarse Lower Sorbian.

Most comments to this section focused on the current situation of Lower Sorbian in Lower Lusatia and what could be done to improve it:

(29) Official status of the language, signage, Sorbian classes for everyone... all these measures and status symbols will not contribute to the revival of the language. First of all we must strive for it that people actually speak Lower Sorbian and then we can care for things like that.

(30) Making the language obligatory in specific contexts could cause aversion and antipathy. I think that active promotion and setting a good example can bring more. Whoever knows whether Sorbian would survive another fight against an active opposition. Everything depends on whether one can succeed to achieve a positive attitude of the majority of the people towards Sorbian.

(31) The language could develop as an effective unique selling point of Lower Lusatia in the future. In terms of tourism and economy, as well as educational policy and, due to it being closely related to the Polish language, also as a bridge to Poland itself.

It is also important to note that the comments themselves expressed many attitudes that were not elicited by the survey:

(32) Germany should finally recognize and reward the Sorbian nation for being loyal and peaceful despite having been discriminated against. The Sorbs have never expressed their demands and wishes with criminal energy but always with cultural energy. With that, Lusatian Sorbs deserve any support from the German state and German nation necessary to keep Sorbian language and culture alive.

This proves that including attitude statements in the questionnaire was the right decision, as it triggered expressions of attitude on other issues in the comments.

\section{Conclusions}

This article has presented and briefly commented on almost all of the 30 questions included in the survey of Lower Sorbian speakers. As has been mentioned before, the survey, with its 78 answers, cannot be considered representative; this does not at all mean that it was not useful, however. It provided important insights into the practices and attitudes of speakers, most of whom could be considered as new speakers. It painted a picture of a group of people of "productive" age (working or studying), who are well-educated or currently obtaining a higher or vocational education. While most of the group do not use Lower Sorbian at home with their families (of origin), the language features in their professional and social life. We can thus speculate that some of them work in the Sorbian institutions, while others are engaged in voluntary work for the preservation of Lower Sorbian language and culture.

Our respondents thus match the profile of a typical new speaker developed in the literature (e.g. Grenoble, 2011; McLeod \& O'Rourke, 2015) in all respects, with one arguable exception - being urban. The survey showed that while many (about 1/3) respondents lived in Cottbus and several resided in cities outside Lusatia, the majority resided in Lower Lusatian villages 
around Cottbus, painting a picture of a rather dispersed and fragmented network. On the other hand, it can be assumed that most of these village dwellers commute to Cottbus for work and social/cultural activities on a daily basis. Taking into account the age and professional situation of our respondents, which suggest mobility, it can be expected that the relative isolation of their homes does not play a role when it comes to their use of Lower Sorbian. Only one respondent mentioned in a comment that they lived too remotely to be able to use the language regularly.

The survey answers also suggest that our respondents are aware of the precarious situation of Lower Sorbian, care about its preservation and/or revitalization, consider using the language with their children in the future, and, as especially visible in the comments to section 4 , have strong attitudes towards the current institutional measures of support for the language and specific ideas about how to improve them. Since making comments in the free fields was completely voluntary, this suggests that our respondents do ponder or have pondered on these issues at some point in their lives, rather than being "forced" to construct opinions on them when completing the questionnaire.

Another important point raised by the survey is the ability of Lower Sorbian to function as a community language in the context of das ständige deutsche Umfeld "the constant German environment" (a respondent's comment). Our respondents noted the difficulties in using Lower Sorbian on a daily basis. While there may be several budding communities of practice using Lower Sorbian - regular pub meetings, family groups, the community of young people around the radio project Bubak, etc. - the problem remains that the contexts where Lower Sorbian is spoken must be planned, organized and controlled, resulting in a somewhat artificial and hardly spontaneous language use. Outside these contexts, German persists as the default language. Lower Sorbian needs language domains and contexts in which it is not an end in itself, but a means to communicate about other issues, and in which its use does not need to be "marked" as enforced or imposed, but instead becomes a matter of course.

To finish on a positive note, the Lower Sorbian adult immersion program Zorja, ${ }^{1}$ currently being developed by young activists who are new speakers themselves, has a chance to become such a context for, admittedly, a small number of learners. If successful in obtaining the necessary funding, the program may recruit participants from among our survey respondents, who displayed their appreciation for and commitment to Lower Sorbian language and culture.

\section{References}

Coleman, S., \& Ross, K. (2010). The media and the public: "Them" and "us" in media discourse. WileyBlackwell. https://doi.org/10.1002/9781444318173

Dołowy-Rybińska, N. (2012). Witalizacja i rewitalizacja — strategie zachowania języków mniejszościowych na Górnych i Dolnych Łużycach. In G. B. Szewczyk (Ed.), Serbołużyczanie wobec tradycji $i$ wyzwań wspólczesności: Język - Literatura - Kultura (pp. 39-57). "Śląsk".

Dołowy-Rybińska, N., \& Ratajczak, C. (2019a). Languages and cultures in contact: The place of new speakers in the education system in Upper Lusatia. Cognitive Studies / Études cognitives, 2019(19), Article 1901. https://doi.org/10.11649/cs.1901

Dołowy-Rybińska, N., \& Ratajczak, C. (2019b). SMiLE = Sustaining Minority Languages in Europe: Project financed by the Smithsonian Center for Folklife \& Cultural Heritage [Unpublished materials].

Glaser, K. (2007). Minority languages and cultural diversity in Europe: Gaelic and Sorbian perspectives. Multilingual Matters. https://doi.org/10.21832/9781853599330

Grenoble, L. A. (2011). Language ecology and endangerment. In P. K. Austin \& J. Sallabank (Eds.), The Cambridge handbook of endangered languages (pp. 291-311). Cambridge University Press.

Hornsby, M. (2015). Revitalizing minority languages: New speakers of Breton, Yiddish and Lemko. Palgrave Macmillan. https://doi.org/10.1057/9781137498809

Hornsby, M., Dołowy-Rybińska, N., Chojnicka, J., \& Toutous, J. (in press). The ideological foundations of Breton and Lower Sorbian language revitalization through education and their consequences for new speakers. International Journal of Bilingual Education and Bilingualism.

\footnotetext{
${ }^{1}$ https://www.zorja.org/
} 
Jodlbauer, J., Spiess, G., \& Steenwijk, H. (2001). Die aktuelle Situation der niedersorbischen Sprache. Domowina Verlag.

Lewaszkiewicz, T. (2014). Dolnołużycki i górnołużycki — języki zagrożone czy wymierające? Slavia Occidentalis, 71(2), 37-53.

Lower Sorbian in Germany. (n.d.). Mercator: Wiki on minority language learning. https://wiki. mercator-research.eu/languages:lower_sorbian_in_germany

Marti, R. (1990). Probleme Europäischer Kleinsprachen Sorbisch und Bündnerromanisch. Otto Sagner. https://doi.org/10.3726/b12999

McLeod, W., \& O'Rourke, B. (2015). "New speakers" of Gaelic: Perceptions of linguistic authenticity and appropriateness. Applied Linguistics Review, 6(2), 151-172. https://doi.org/10.1515/ applirev-2015-0008

Norberg, M. (1996). Sprachwechsel in der Niederlausitz: Soziolinguistische Fallstudie der deutschsorbischen Gemeinde Drachhausen/Hochoza. Uppsala University.

Acknowledgment

This research has been financed by the Polish National Science Centre (Narodowe Centrum Nauki) under the grant no. NCN OPUS 162018/31/B/HS2/00844.

The author declares that she has no competing interests.

20 This is an Open Access article distributed under the terms of the Creative Commons Attribution 3.0 PL License (http: //creativecommons.org/licenses/by/3.0/pl/), which permits redistribution, commercial and non-commercial, provided that the article is properly cited.

() The Author 2021

Publisher: Institute of Slavic Studies, Polish Academy of Sciences

Publishing history: Received 2021-03-22; Accepted 2021-07-27; Published 2021-10-11. 